\title{
Preliminary Research on Governance Modernization of Large State-owned Corporate Group
}

\author{
Gang Lu ${ }^{1, a^{*}}$, Jin Liu ${ }^{1, b}$ and Youzi Wang ${ }^{1, c}$ \\ ${ }^{1}$ State Grid Energy Research Institute, Beijing, China \\ alugang@sgeri.sgcc.com.cn, 'biujin@sgeri.sgcc.com.cn, 'Wangyouzi@sgeri.sgcc.com.cn
}

Keywords: State-owned Enterprises; Governance; Group; Modernization; Control

\begin{abstract}
Large state-owned corporate groups generally face the problems of governance modernization. By focusing the particularity of large state-owned group governance, based on advanced corporate governance theories, the paper proposes the theoretical framework and business strategy of transforming from the governance structure, governance capability, implementation principle and strategic priorities into the governance modernization, . It comprehensively strengthens the relevant understanding both in theory and practice.
\end{abstract}

\section{Introduction}

State-owned enterprise is an important force to promote the national modernization and safeguard the interests of people. The level of governance is associated with the fate of enterprises and national economic competitiveness. Since the 1990s, by separating the government functions from the business management and state-owned enterprises reform, the Chinese state-owned enterprises have rapidly enhanced the governance level, so some state-owned enterprises have gradually become modern enterprises. However, the Chinese state-owned enterprises are deeply affected by the planned economic system, facing problems on internal extensive management, imperfect motivation and restrictive mechanism, lagging management ideas and methods. Therefore, corporate governance has become an issue of transition to modernization. At present, the academia has conducted researches on this topic and has achieved remarkable results [1-9]. Nevertheless, due to the slow progress in practice as well as the inadequate understanding on corporate governance, theoretical researches do not exactly match business practices, and practical problems need to be resolved. Large state-owned corporate group are facing more complicated situations and challenges on governance modernization because of the complex organizational structure, so the theoretical research has more practical significances.

This paper studies from the general concept of corporate governance, combines with the specificity analysis of large state-owned corporate group governance, puts forward the theoretical framework of transiting large state-owned enterprises to governance modernization from the governance structure and governance capability, and explores related practical measures from the principles and strategic priorities.

\section{Corporate Governance Issues}

The general concept of corporate governance consists of narrow and broad senses. From the narrow sense perspective, corporate governance refers to the corporate legal person, namely, the authorization and regulation system at ownership level. This paper adopts the broad concept. Corporate governance refers to reasonably arrange the relationship between corporate responsibility and rights of related parties and achieve coordinated operation and effective balance of enterprises. Compared with management, the governance emphasizes on the participation, mutual collaboration and balance of multiple subjects. 
Corporate governance issues become increasingly complex by the challenges of group, globalization and cybereconomy [7, 9]. Generally speaking, corporate governance structure specifically refers to authorization and regulation at ownership level. However, the complex organizational structure of the group brings the difficulties on coordination between business interests and the protection, and its responsibilities and rights allocation have exceeded the single corporate governance structure. Globalization causes corporate governance to face challenges of different national political systems and diverse social culture. Cybereconomy brings discussion on the governance of network organization, expanding the means and forms of governance.

Large state-owned enterprises governance is special. Chinese large state-owned enterprises are generally facing problems of governance modernization tasks. Compared with market-oriented enterprises, they are having issues on absence of owners, equity simplification, long-term planned economy system, and group decentralized management. Large state-owned enterprises have to address three points in order to achieve the governance modernization. Firstly, establish the group corporate governance structure, and solve the problems on the unbalance of "new three committees", non-transparent major business information, nonstandard decision-making mechanism and imperfect restraint mechanism. Secondly, form the group cohesive force to improve the loose group management and weak implementation. Thirdly, improve the basic system of modern enterprise to solve the problems that managers accept only higher but lower position, employees can be hired but not fired, and income can be increased but not decreased.

\section{Theoretical Framework of Large state-owned Corporate Group Governance Modernization}

Large state-owned corporate group governance modernization refers to the process of building corporate governance system which is based on modern property theory, contract theory of modern enterprise, principal-agent theory and stakeholder theory, and complies with business management rules and era peculiarities, and achieves scientific decision-making, risk control and value maximization. The essence is to build the overall transformation of modern corporate system, the object is corporate group, and the core is the modernization of governance structure and governance capability. A scientific governance structure is the foundation, which forms the organizational and operational mechanism to make sure the rules available at system level; the operation; a good governance capability is the key, which forms the rules available at system construction level and implementation level, to have a decisive impact on the final results of governance.

(1) "Modern" governance structure should be featured by "complete system, diverse subject, scientific system and sound function".

"Complete system" - as a multiple-legal-person union, the corporate group have a double-nature modern governance structure. Firstly, form a sound legal person governance structure at the group level, and build the perfect rights, decision-making, implementation and oversight bodies; secondly, construct the group operation system with reasonable organization form and scientific power allocation, and effectively solve the governance issues at all levels of the group (including multinational governance brought by international companies).

"Diverse subject" - the modern governance structure should guarantee the governance subject is diverse, and realize the participation and governance of various interest parties. The structure should make various governance bodies play their roles independently. The structure should also realize the two-way interaction from top to bottom, from bottom to top and horizontal communication.

"Scientific system" - the modern governance structure should build a collaborative, balanced and motivated system. Collaboration means the collaboration with "control" and "governance", and build the system with control science, internal control mechanism and standard fundamental management; balance means to take rules, compliance and accountability as the main element, and determine the system of labor division and mutual supervision; motivation means to take labor, personnel and 
allocation system reform as the breakthrough, and form a set of motivation mechanism by coordinating the reasonable authorization and reputation.

"Sound function" - modern governance structure has four functions. Scientific decision-making function means to protect and maximize the interests of shareholders; group operation function means to achieve the global allocation of elements and resources; accountability function refers to implement internal supervision and responsibility investigation over all governance bodies, and guarantee the equalities between rights and responsibilities; safeguard the healthy ecosystem function means to perform the extensive social responsibility, gather the social cohesion and achieve win-win situation.

(2) The "modernization" of governance capability is the modernization of concepts, styles, tools and qualities.

"Concept modernization" - manage enterprises according to law, change the "management by person" only by the competency of entrepreneurs; insist the balance concept, decide everything by one person change the situation of insufficient constraint of major decisions; open and transparent, eliminate the black box operation; maximize the integrated value, and change the "self-rotation" of management without control; insist on win-win situation and change the single governance body.

"Method modernization" - rely on strict and efficient institutional system for personnel, power and affairs management to achieve interaction; use market-based micro-management mechanism to form the competitive pattern which emphasizes cost, effectiveness and efficiency; publicize outstanding business culture to unite the people and improve efficiency; utilize external supervision, take the initiative to make promise, listen to the opinions and accept supervision.

"Tools modernization" - use modern management tools and information network, expand governance tools and boundaries, reduce the governance costs, and adapt to the new situation of network governance.

"Quality modernization" - create high-quality and vibrant governance body and staff team, and comprehensively enhance the ability of decision-making, management, coordination, supervision, motivation and execution.

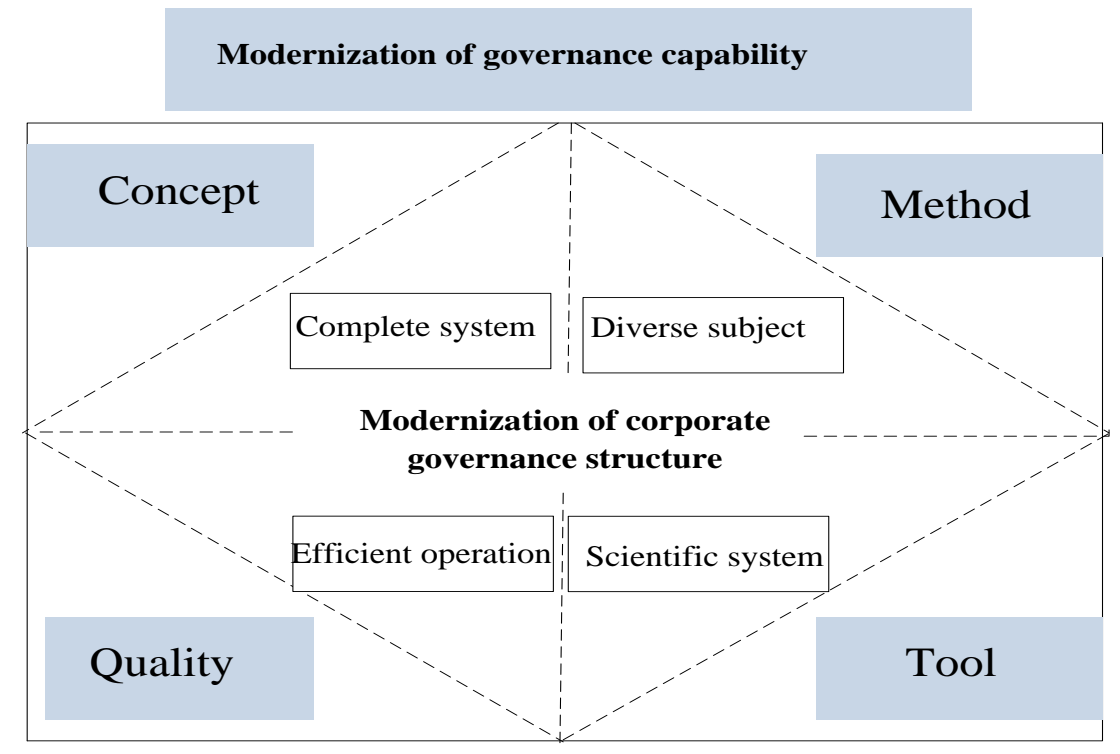

Fig. 1 Modernization of Large State-owned Enterprise Governance

\section{Practical Suggestions}

To promote the governance modernization, large state-owned enterprises should build a scientific system at the group level that can implement the corporate mission and responsibility and ensure scientific decision-making, so as to avoid the balance failure and loss of risk control caused by absence of the owner and equity simplification (separation of ownership and operation). Secondly, the focus 
inside the group is to solve the special problem of decentralized operation and inefficient coordination in large state-owned enterprises. Above all, governance modernization is a process that transforms from "management by person" to "managing enterprises according to law", transforms from "self-rotation" of management without control to group operation, and transforms from single governance body to diverse interest parties and comprehensive value maximization.

Implement the principles of governance modernization. Four principles should be followed in the process. The first principle is national conditions and business conditions. According to experience from all countries, legal, politics, cultural, history and other social factors, ownership structure, grid operational characteristics, development stage and other business characteristics determine the selection of group corporate governance structure. The second principle is integration. The corporate governance structure at group level should not be separated from the governance structure at all group levels and international companies. The third principle is coordination and balance. The aim is to form joint forces to construct balance mechanism. The fourth principle is the unity of structure and capabilities in order to realize legal basis and compliance with laws.

Implement strategic focus of governance modernization. Under the new situation of deepening the reform, national governance structure and governance capability modernization [10], state-owned corporate governance modernizations need to strengthen top-level design, strategically consider the corporate governance, group control, mixed ownership and etc., coordinate with different governance structures, and implement the comprehensive transformation to corporate governance structure and governance capability modernization .

Firstly, according to SASAC requirements and corporate features, large state-owned enterprises should make an advanced study of the board of directors and subsidiary professional committee, clarify the function positioning and responsibilities of new and old three committees, and effectively play different roles.

Secondly, large state-owned enterprises should re-examine the original group control system with the governance thinking, further optimize the corporate level, establish the bottom-up feedback mechanism that can scientifically "regulate" the decisions, and stimulate the grassroots innovation vitality.

Thirdly, large state-owned enterprises should speed up the trend based on the corporate globalization process, form systematic multinational management strategies, optimize the ownership structure, improve the international business management and control system, and improve the corporate cultural cohesion mechanisms and stakeholder governance mechanism.

Fourthly, large state-owned enterprises should carry out equity diversity reform over the conditional subordinate piloted units, and improve the governance structure by relying on external forces.

Fifthly, large state-owned enterprises should further establish the thinking of rule of law, strongly regulate the prominent problems, strictly control key links, implement the general management system, and achieve business construction with the rule of law.

\section{Conclusions}

This paper discusses the large state-owned corporate group governance modernization, gives a theoretical understanding of the framework, and proposes strategic measures and suggestions close to actual conditions. Practically, more researches with business features of corporate groups should be investigated. In the next step, the requirements and impacts of state-owned corporate reforms, mixed ownership and other policies should be fully considered for further researches. 


\section{References}

[1] Zhang Qianzhi. Group Governance and Control [M]. 2012 Beijing: Social Sciences Academic Press.

[2] Sun Liancai. Corporate Group Control [M]. Beijing: Economic Science Press, 2009.

[3] Wang Jipeng. Group Control (2nd Edition) [M]. Beijing: China CITIC Press, 2008.

[4] Xie Mingliang. Research on Corporate Group Governance from the Perspectives of Coordination and Cooperation [M] Beijing Economic Science Press, 2012.

[5] Peng Zhengxin. Research on Chinese State-owned Corporate Group Governance [D] Chongqing University, 2003.

[6] Du Xinyue. Research on Chinese State-owned Corporate Group Governance Mechanism [D]. Capital Normal University. 2013.

[7] Li Weian. Corporate Governance (2nd Edition) [M]. Beijing: Higher Education Press, 2009

[8] Zhang Dongfeng, Ren Aiying. Cultivation of Corporate Governance Ability _ Reengineering Corporation (Group) System Platform [J]. Hebei Enterprise. No. 10, 2004.

[9] Li Weian. Response to Governance Gap and Improvement of Group Corporate Multinational Governance [J] Nankai Business Review. No. 1, 2011.

[10] Zhang Xiaojin and Yu Xiaohong. Six Speeches on Implementing National Governance System and Governance Capability Modernization [M]. Beijing: People's Publishing House, 2012. 